\title{
NUP62: the target of an anti-sperm auto-monoclonal antibody during testicular development
}

\author{
Risako Oda-Sakurai ${ }^{1,2}$, Hiroshi Yoshitake ${ }^{1}$, Yoshiki Miura $^{3}$, Saiko Kazuno $^{3}$, Takashi Ueno $^{3}$, \\ Akiko Hasegawa ${ }^{4}$, Kenji Yamatoya ${ }^{1}$, Kenji Takamori ${ }^{1}$, Atsuo Itakura ${ }^{2}$, Hiroshi Fujiwara ${ }^{5}$, \\ Satoru Takeda ${ }^{2}$ and Yoshihiko Araki ${ }^{1,2}$ \\ ${ }^{1}$ Institute for Environmental \& Gender-specific Medicine, Juntendo University Graduate School of Medicine, \\ Urayasu, Chiba, Japan, ${ }^{2}$ Department of Obstetrics \& Gynecology, Juntendo University Graduate School of \\ Medicine, Bunkyo, Tokyo, Japan, ${ }^{3}$ Laboratory of Proteomics \& Biomolecular Science, Research Support Center, \\ Juntendo University Graduate School of Medicine, Bunkyo, Tokyo, Japan, ${ }^{4}$ Department of Obstetrics \& Gynecology, \\ Hyogo College of Medicine, Nishinomiya, Hyogo, Japan and ${ }^{5}$ Department of Obstetrics \& Gynecology, Kanazawa \\ University Graduate School of Medical Sciences, Kanazawa, Ishikawa, Japan
}

Correspondence should be addressed to Y Araki; Email: yaraki@juntendo.ac.jp

\begin{abstract}
Ts4, an autosperm-monoclonal antibody (mAb), reacts with a specific oligosaccharide (OS) of glycoproteins containing bisecting $\mathrm{N}$-acetylglucosamine residues. Ts4 reactivity was observed against epididymal spermatozoa, testicular germ cells, and the early embryo, but not against major organs in adult mice. In mature testis, Ts4 exhibits immunoreactivity with a germ cell-specific glycoprotein, TEX101, whereas the mAb immunoreacts with alpha- $N$-acetylglucosaminidase in the acrosomal region of cauda epididymal spermatozoa. Thus, Ts4 seems to react against different molecules throughout spermiogenesis via binding to its OS epitope. Since the Ts4-epitope OS is observed only in reproduction-related regions, the Ts4-reactive OS may play a role in the reproductive process. The aim of this study is to investigate the characteristics of the Ts4-reactive molecule(s) during testicular development. Ts4 reactivity was observed in testes from the prenatal period; however, its distribution changed according to the stage of maturation and was identical to that of the adult testes after 29-day-postpartum (dpp). Ts4 immunoreactivity was detected against a protein with $63 \mathrm{kDa}$ in testis from 1 to $29 \mathrm{dpp}$. In contrast, Ts4 showed reactivity against some other glycoproteins after 29 dpp, including TEX101 at the 5-week-old stage and onward. To identify the Ts4-reactive $63 \mathrm{kDa}$ molecule, we identified NUP62 as the target of Ts4 in 22 dpp testis using liquid chromatography-tandem mass spectrometry analysis. Because NUP62 has been known to play active roles in a variety of cellular processes including mitosis and cell migration, the bisecting GlcNAc recognized by Ts4 on NUP62 may play a role in regulating the early development of germ cells in male gonadal organs.
\end{abstract}

Reproduction (2019) 158 503-516

\section{Introduction}

Fertilization based on the gamete interaction is believed to be a carbohydrate-mediated event (Tulsiani et al. 1997, Diekman 2003, Defaus et al. 2016). During previous investigation into the pathophysiology of anti-sperm auto (ASA) antibodies (Abs) that affect the fertilization process, we previously generated several ASA-monoclonal Abs (mAbs) from immunologically naïve aged male mice. We targeted molecules in the acrosomal region of epididymal spermatozoa for $\mathrm{mAb}$ production (Yoshitake et al. 2008a), because sperm molecules having important roles for fertilization are believed to be located in the head region. Among the mAbs established, one (termed Ts4) reacted to glycoproteins in the epididymal sperm head and testicular proteins (Yoshitake et al. 2008a). Its epitope is a specific sugar moiety of testicular glycoproteins containing agalacto-biantennary $\mathrm{N}$-glycan with bisecting $\mathrm{N}$-acetylglucosamine (GlcNAc) carrying fucose residues (Yoshitake et al. 2015).

Bisecting GlcNAc is a $\beta 1,4$-linked GlcNAc residue attached to a $\beta$-mannose of the $N$-glycan core, which is an enzymatic production of $\mathrm{N}$-acetylglucosaminyltransferase (GnT)-III (Narasimhan et al. 1982). For example, GnT-III is reported to add bisecting GlcNAc to EGF receptor and adhesion molecules (e.g., $\alpha_{5} \beta_{1}$ integrin and E-cadherin) and to alter their functions (Rebbaa et al. 1997, Kitada et al. 2001, Isaji et al. 2004); therefore, the bisecting GlcNAc structures are thought to play a role in biological functions, such as cell growth and adhesion by regulating cell-surface glycoproteins. These results indicate that the oligosaccharide (OS) structure also has potential 
function(s) in the fertilization process. Histochemical analysis using Phaseolus vulgaris erythroagglutinin (PHA-E, a lectin known to recognize complex type $\mathrm{N}$-glycans containing bisecting GlcNAc (Narasimhan et al. 1986)) has shown that bisecting GlcNAc exists in testicular and epididymal germ cells (Lee \& Damjanov 1985). However, its biological function in reproductive processes remains incompletely understood.

Our previous studies revealed specific immunoreactivity of Ts4 against reproduction-related regions, including the acrosomal region of epididymal spermatozoa, the plasma membranes of spermatocytes/ spermatids within the seminiferous tubules in adult mice, and the early embryo. However, the immunoreactivity was not observed against the ovary or other major somatic organs (Shirai et al. 2009, Yoshitake et al. 2015). In matured male organs (epididymis and testis), Ts4 immunoreacts against several distinct glycoproteins (Shirai et al. 2009). Among these glycoproteins, we identified alpha-N-acetylglucosaminidase (Naglu, a degradation enzyme of heparan sulfate) and TEX101 (a germ cell-marker glycoprotein with an essential role in fertilization in vivo (Kurita et al. 2001, Fujihara et al. 2013)) as possessing the Ts4-recognized bisecting GlcNAc in the epididymal spermatozoa and testicular germ cells, respectively, in adults (Yoshitake et al. 2008a, 2016). In the early embryo, Ts4 reacted against unknown molecules apart from TEX101 (Shirai et al. 2009). These results indicate that the core peptide structure of glycoproteins possessing Ts4-reactive bisecting GlcNAc differ among the epididymal spermatozoa, testicular germ cells, and the early embryo. Based on these findings, we speculated that the expression pattern of such glycoproteins may vary across different stages of male germ cell differentiation and proliferation.

Our ultimate goal is to elucidate the biological significance of Ts4-reactive bisecting GlcNAc in the mammalian reproductive system. As an initial step, in the present study we investigated the molecular expression and chemical characteristics of molecules equipped with Ts4-reactive bisecting GlcNAc in male gonads during development. Furthermore, we identified a glycoprotein possessing Ts4-reactive bisecting GlcNAc at an early developmental stage of spermatogenesis using immunoprecipitation combined with liquid chromatography (LC)-tandem mass spectrometry analysis (MS/MS).

\section{Materials and methods}

\section{Animals}

Female/male ICR mice (3-15-week old) were from Sankyo Lab Service (Tokyo, Japan). They were maintained and bred at our animal facilities under 12L:12D conditions, and given free access to food and water. Animal experimental protocols were approved by the ethical committee for laboratory animals (the approved \#270026), and all procedures were conducted according to the guide for care and use of laboratory animals, Juntendo University. For mated animals, observation of the vaginal plug was considered as 0 -day postcoitus $(\mathrm{dpc})$, and the day they were born was regarded as 1 day postpartum (dpp) for neonatal mice.

\section{Antibodies}

Ts4 (mouse IgM) was established as previously described (Yoshitake et al. 2008a). RP-3 (an anti-rat polymorphonuclear leukocyte mAb, mouse IgM) used for control studies, TES101 (an anti-TEX101 mAb which reacts only under non-reducing conditions, mouse IgG1), 6035 (an anti-TEX101 mAb which reacts under either reducing and non-reducing conditions, mouse IgG2a), $3 \mathrm{H} 9$ (an anti-human GPI-80 mAb, used as negative control mAb of TES101, mouse IgG1), and antidipeptidase 3 (DPEP3) polyclonal antibody (pAb) (rabbit IgG) were generated and purified as previously reported (Sekiya et al. 1989, Suzuki et al. 1999, Kurita et al. 2001, Yoshitake et al. 2008a, 2011). Other Abs were from the following companies: negative control mouse and rabbit immunoglobulins (Ig), horseradish peroxidase (HRP)-conjugated rabbit anti-mouse and goat anti-rabbit Ig pAbs (DAKO), anti-DDX4/MVH pAb (rabbit IgG) (Abcam), anti-nuclear pore glycoprotein p62 (NUP62) pAb (rabbit IgG) (Proteintech Japan, Tokyo, Japan), anti-CD73 pAb (sheep IgG), and negative control sheep Ig ( $R$ and D systems), HRP-conjugated goat anti-mouse IgM pAb (Merck Millipore), HRP or Alexa Fluor 594-conjugated donkey anti-sheep Ig pAb, Alexa Fluor 488-conjugated goat anti-mouse IgM, and Alexa Fluor 594-conjugated goat anti-rabbit IgG pAbs (Thermo Fisher Scientific). Summary of primary antibody details and their dilutions used in immunohistochemistry/ Western blot analyses are listed in Supplementary Table 1 (see section on supplementary data given at the end of this article).

\section{Immunohistochemistry}

For organ isolation, mice were anesthetized with $3 \%(\mathrm{v} / \mathrm{v})$ sevoflurane (Pfizer Japan Inc.) in oxygen, and then the total blood was eliminated by flushing the left ventricular lumen with phosphate-buffered saline (PBS; $\mathrm{pH}$ 7.4) and draining blood from right atrium. The removed fresh organs were fixed with Bouin's solution (Sigma-Aldrich) overnight at $4^{\circ} \mathrm{C}$ and then embedded in paraffin wax until use. Sections were de-paraffinized in xylene, washed in ethanol and then rehydrated in PBS. After blocking in 4\% goat serum or Block Ace (Megmilk Snow Brand Co., Ltd., Sapporo, Japan) for $1 \mathrm{~h}$ at room temperature (RT), and the specimens were probed with appropriate concentration of primary Abs (Supplementary Table 1) in PBS overnight at $4^{\circ} \mathrm{C}$, and then washed three times in PBS containing 0.05\% Tween 20 (Nacalai tesque, Kyoto, Japan) (PBST). Subsequently, the sections were incubated with Alexa Fluor 488- or 594-conjugated secondary Abs $(2 \mu \mathrm{g} /$ $\mathrm{mL}$ ) at RT for $1 \mathrm{~h}$. After rinsing with PBST three times, the sections were counterstained with TO-PRO3 (Thermo Fisher Scientific) for 20 min at RT, washed with PBST three times, and then mounted in Ultramount Aqueous Permanent Mounting Medium (DAKO) on glass microscope slides (Matsunami 
Glass, Osaka, Japan). The stained samples were observed under a confocal laser microscope (TCS SP5 AOBS, Leica). Control sections received the same treatment with an isotypematched control Ab.

\section{Preparation of mouse tissue extracts}

Tissues from ICR mice were separated into three fractions, the extracellular (EC), the water-soluble (WS), and the Tritonsoluble (TS) fractions, according to the methods essentially as described previously (Yoshitake et al. 2008a,b, 2015). In some cases, to prepare tissue extractions from mice under 29-dppold, the tissues were extracted as follows; after homogenizing by 20 strokes with a glass homogenizer in PBS containing $1 \times$ EDTA-free complete inhibitor cocktail (Roche Diagnostics $\mathrm{GmbH})$, the sample wereas subsequently extracted by Digital homogenizer for $10 \mathrm{~s}$, six times. Then Triton X-100 was added to the final concentration of $1 \%$. Following a $20 \mathrm{~min}$ incubation, the suspension was ultracentrifuged at 114,000 $\mathbf{g}$ for $30 \mathrm{~min}$, and the resultant supernatant was designated as the whole protein (WP) fraction. All subsequent steps were performed on ice. All samples were stored at $-80^{\circ} \mathrm{C}$ until use.

\section{SDS-PAGE and Western blot analysis}

The proteins were separated by 1D or 2D SDS-PAGE system, and Western blot analysis was performed according to the published methods (Yoshitake et al. 2011, 2015). The transblotted membrane was blocked in $2 \%$ skim milk, and then incubated with appropriate concentration of primary Abs (Supplementary Table 1) overnight at $4^{\circ} \mathrm{C}$. After washing, the membrane was incubated with HRP-conjugated secondary Abs for $1 \mathrm{~h}$ at RT, followed by detection using ECL Western blotting detection system (GE Healthcare Life Sciences), and then exposed on an X-ray film (BioMax XAR Film, Eastman Kodak Company, Rochester, NY, USA). In some cases, the results from Western blot was digitized into an Apple iMAC computer (Apple Inc., Cupertino, CA, USA), and the relative density was traced using ImageJ 1.52 (http://imagej.nih.gov/ij) for relative quantitation.

\section{Immunoprecipitation}

Immunoprecipitation using Ts4 and TES101 was performed essentially according to the method described previously (Yoshitake et al. 2011, 2015). Immunoprecipitation using the anti-CD73 pAb or the anti-NUP62 pAb was performed by Dynabeads Protein G or Protein A (Thermo Fisher Scientific), respectively, according to the manufacturer's instructions. Briefly, $10 \mu \mathrm{g}$ of the anti-CD73 pAb or negative control sheep Ig was conjugated with $1.5 \mathrm{mg}$ of Dynabeads-Protein G. The antibodies were crosslinked to the beads to avoid co-elution of the antibodies. The testicular extracts were immunoreacted with each antibody-conjugated bead on a rotary shaker for $10 \mathrm{~min}$ at RT. In the case of NUP62, $4 \mu \mathrm{g}$ of the anti-NUP62 $\mathrm{pAb}$ or negative control rabbit Ig was immunoreacted with $100 \mu \mathrm{g}$ of the testicular extract for $12 \mathrm{~h}$ at $4^{\circ} \mathrm{C}$. Then, $360 \mu \mathrm{g}$ of Dynabeads-Protein A were added to the mixture and then incubated at $4^{\circ} \mathrm{C}$ for another $12 \mathrm{~h}$. After washing, the beads were incubated with $3 \times$ SDS sample buffer for $10 \mathrm{~min}$ at $70^{\circ} \mathrm{C}$. The solubilized proteins were then used as samples for SDS-PAGE.

\section{Silver staining}

After the protein solutions were separated by SDS-PAGE, silver staining was performed using PlusOne Silver Staining kit (GE Healthcare Life Sciences) as described previously (Tsukamoto et al. 2006). The silver-stained gels were stored in $10 \%$ acetic acid solution at $4{ }^{\circ} \mathrm{C}$ until analyzed.

\section{In-gel digestion}

In-gel trypsin digestion of the protein was performed according to the method as described previously (Tsukamoto et al. 2006). After digestion, resulting peptide mixtures were extracted with $1 \%$ formic acid $/ 50 \%$ acetonitrile solution, and then concentrated with a speed vacuum to a final volume of 5-10 $\mu \mathrm{L}$ for further analysis by LC-MS/MS.

\section{LC-MS/MS}

Proteins were identified by nano-LC-MS/MS using a Triple TOF 5600 system operated with Analyst TF 1.7 software and an Eksigent nano LC system (AB SCIEX, Framingham, MA, USA). The obtained MS data was searched with ProteinPilot 5.0.1 Software (AB SCIEX) using UniProt database (2018_11). A confidence cutoff of $1 \%$ false discovery rate was applied for protein identification.

\section{Results}

\section{Morphological immunoreactivity of Ts4 at various stages of testicular development}

To reveal the immunoreactivity of Ts4 against testis from the embryonic stage to the puberty, we first performed an immunofluorescence study of mouse testes from $14 \mathrm{dpc}$ to maturity. In testes from $14 \mathrm{dpc}$ to $8 \mathrm{dpp}$, Ts4 showed strong immunoreactivity against cells in the seminiferous tubules, including germ cells (cells that were positive in staining for anti-DDX4/MVH pAb, a marker Ab for the cytoplasm of germ cells (Noce et al. 2001)). Ts4 was slightly reactive with the cells outside of the seminiferous tubules, such as interstitial cells (Fig. 1A, B, C and D). At this stage, the Ts4-positive signals were predominantly observed inside the distribution of DDX4/MVH, indicating that Ts4 principally immunoreacted with the nuclear membrane of germ cells (Fig. 1A, B, C and D). In accordance with testicular development from $15 \mathrm{dpp}$ to 8 weeks after birth, the immunoreactivity was restricted to the seminiferous tubules, unlike before $8 \mathrm{dpp}$. At $15 \mathrm{dpp}$, Ts4 signals were observed in the cytoplasm of spermatocytes (Fig. 1E). During the developing stage at $22 \mathrm{dpp}$, Ts4 showed immunoreactivity mainly against plasma membranes, and faint immunoreactivity in the cytoplasm (Fig. 1F). After 29 dpp, Ts4-positive staining was limited to the plasma membranes, including sperm tails (Fig. 1G, H and I). 


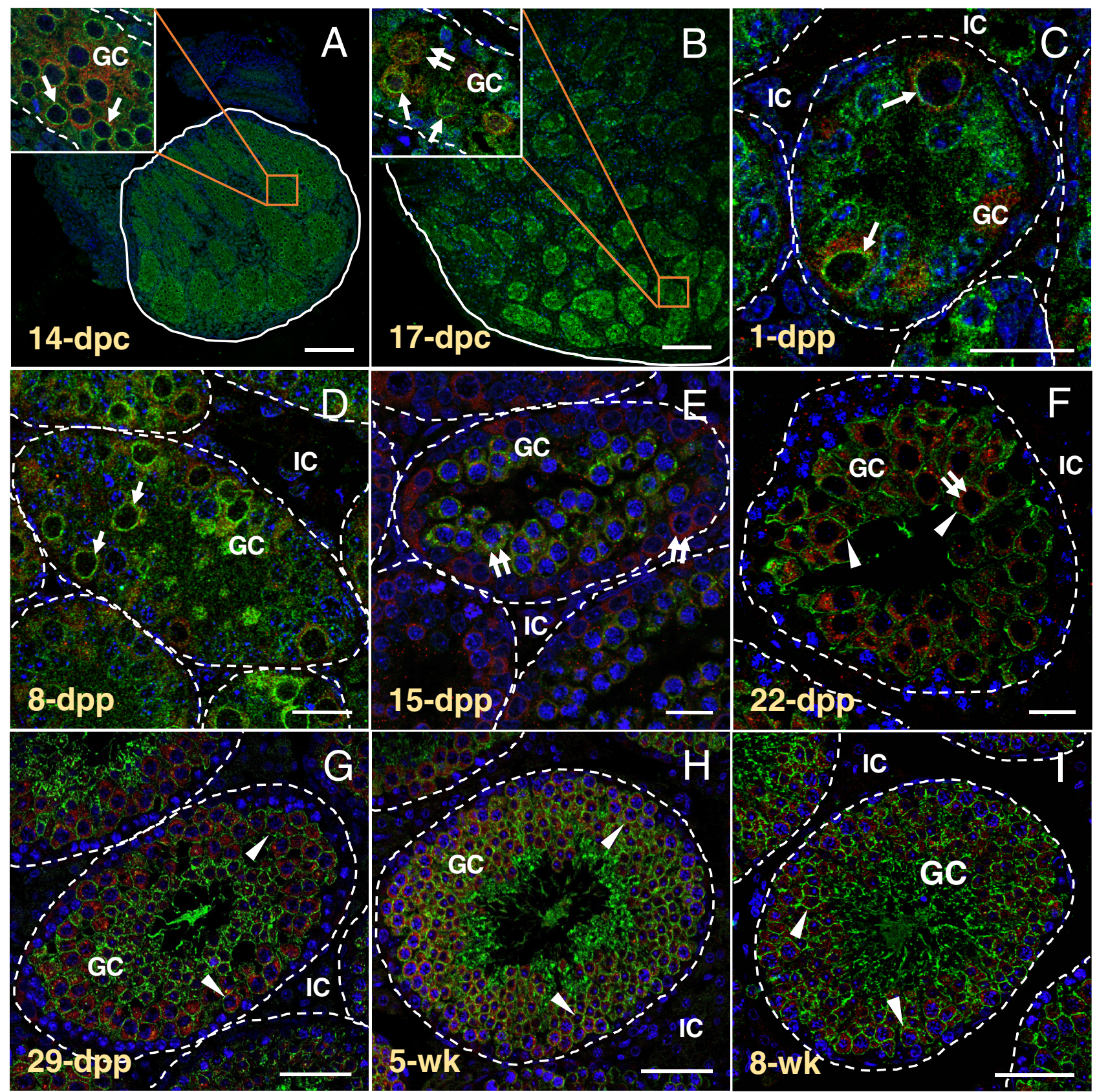

Figure 1 Immunohistochemistry of the developing male mouse reproductive organs using Ts4. The sections from $14 \mathrm{dpc}(\mathrm{A}), 17 \mathrm{dpc}(\mathrm{B}), 1 \mathrm{dpp}$ (C), $8 \mathrm{dpp}(\mathrm{D}), 15 \mathrm{dpp}(\mathrm{E}), 22 \mathrm{dpp}(\mathrm{F}), 29 \mathrm{dpp}(\mathrm{G}), 5$-week (H), and 8-week-old (I) mice were double stained with Ts4 (green) and anti-DDX4/ $\mathrm{MVH} \mathrm{pAb}$ (red), and then counterstained with TO-PRO3 (blue). Bars: $100 \mu \mathrm{m}(\mathrm{A}, \mathrm{B}), 20 \mu \mathrm{m}(\mathrm{C}, \mathrm{D}, \mathrm{E}, \mathrm{F}), 50 \mu \mathrm{m}(\mathrm{G}, \mathrm{H}$, I). Solid and dotted lines show the borders of testes and seminiferous tubules, respectively. GC, germ cells; IC, interstitial cells. The locations of immunopositive staining with the Abs in/on the cytoplasm (double arrows), nuclear membranes (single arrows), and plasma membranes (arrowheads) are indicated in the images, respectively. Insets: Higher magnification images of each seminiferous tubule.

\section{Immunoreactive pattern of Ts4 against developing testicular proteins using Western blot analysis}

We previously revealed that Ts4 detected approximately 38, 110, and $140 \mathrm{kDa}$ bands in sexually mature mouse testicular extracts (Yoshitake et al. 2008a), so that we targeted the TS fraction of testis because Ts4reactive molecules were observed mainly on the plasma membranes of adult testicular germ cells. We reconfirmed this finding in the present study (Fig. 1I). We next investigated whether these same bands were also detected in the developing testes to characterize Ts4reactive molecules. In premature testes, we used WP fraction due to their limitation of sample preparation. Immunoreactivity of testicular extracts from $1 \mathrm{dpp}$ to 22 
dpp mice gradually increased at the apparent molecular mass of $63 \mathrm{kDa}$ (Fig. 2A). In addition, several bands were observed at the molecular masses greater than $100 \mathrm{kDa}$ in the testicular extracts from $29 \mathrm{dpp}$ mice (Fig. 2A). Conversely, the specific bands at 38, 110, and $140 \mathrm{kDa}$ were detected with Ts4 in the TS fraction from 5- to 9-week-old mouse testes (Fig. 2A), as well as in mature testes (Yoshitake et al. 2008a). We previously reported that the $38 \mathrm{kDa}$ band recognized by Ts 4 in the mature testis corresponds to TEX101 during the gonadal development (Kurita et al. 2001, Takayama et al. 2005, Yoshitake et al. 2008a, Shirai et al. 2009). We examined whether the $63 \mathrm{kDa}$ bands observed in $1 \mathrm{dpp}$ to $29 \mathrm{dpp}$ testicular extracts contained a peptide derived from TEX101. A mAb specific to TEX101 (termed TES101) (Kurita et al. 2001) detected a band at an apparent molecular mass of $38 \mathrm{kDa}$ in the testicular extracts from $22 \mathrm{dpp}$ onward (Fig. 2B). Although non-specific bands
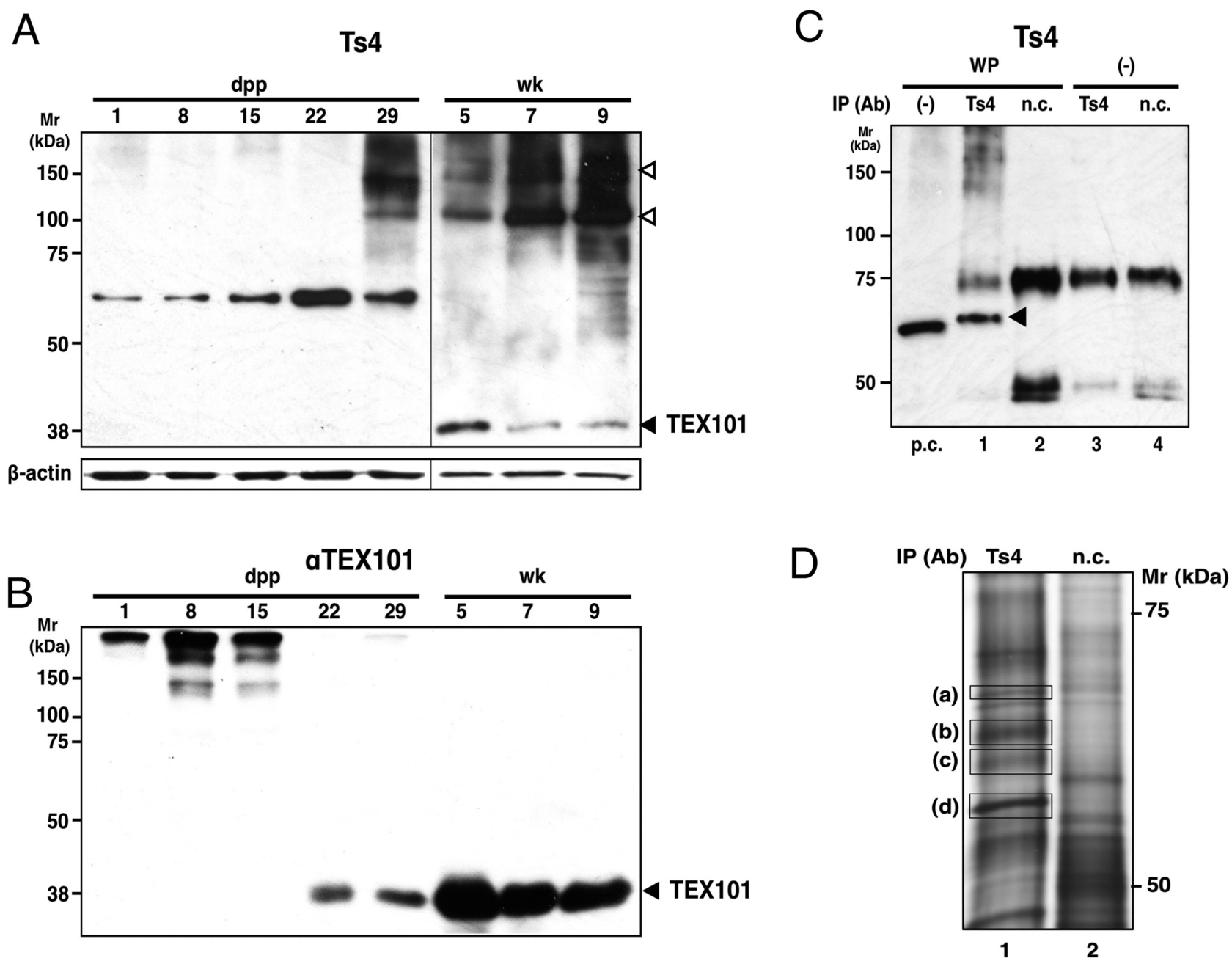

Figure 2 Western blot analysis of the testicular proteins during development and biochemical analysis of testicular proteins in the $22 \mathrm{dpp}$ mice co-immunoprecipitated with Ts4. Testicular WP fractions of 1, 8, 15, 22, and $29 \mathrm{dpp}$ (each $40 \mu \mathrm{g}$ ) and TS fractions of 5-, 7-, and 9-week-old (each $10 \mu \mathrm{g}$ ) were applied to a 7.5\% SDS-PAGE under reducing conditions, electroblotted onto PVDF membrane, and then detected with Ts4 (A). The same samples (each $5 \mu \mathrm{g}$ ) were separated by SDS-PAGE under non-reducing conditions, blotted onto PVDF membrane, and then detected with TES101 (an anti-TEX101 mAb ( $\alpha$ TEX101) (Kurita et al. 2001)) (B). Closed and open arrowheads indicate the specific bands corresponding to TEX101 (approximately $38 \mathrm{kDa}$ ) and unknown proteins (110 and $140 \mathrm{kDa}$ ) previously described (Shirai et al. 2009), respectively. Expression of $\beta$-actin was used as a quantitative internal control. To identify the protein reactive with Ts4 in the premature testis, testicular WP fraction from $22 \mathrm{dpp}$ mice $(20 \mu \mathrm{g})$ (positive control: p.c.) and the immunoprecipitated proteins from the WP fraction with either Ts4 or RP-3 (negative control: n.c.) (lane 1 and 2) were applied to each lane of a 7.5\% SDS-PAGE gel and subjected to Western blot analysis under reducing conditions using Ts4 (C) or visualized by silver staining (D). Immunoprecipitation was performed using testicular WP fraction from $22 \mathrm{dpp}$ mice $(200 \mu \mathrm{g})$ with Ab $(15 \mu \mathrm{g})$ for Western blot analysis (C). For silver staining, twice the amount of that in Western blot analysis was used (D). Other control experiments were conducted under the same conditions, except for the absence of the tissue extract (-) (C; lane 3 and 4). Arrowhead indicates the specific band observed in Western blot analysis. The specific band observed in the silver staining of the Ts4 immunoprecipitants (D; lane 1, (a)-(d)), and the corresponding gel piece in the immunoprecipitated protein using negative control antibody (D; lane 2) were analyzed by LC-MS/MS. IP (Ab), Ab used for immunoprecipitation; Mr, molecular mass. 
larger than $150 \mathrm{kDa}$ were identified in the testicular extracts from 1 to $15 \mathrm{dpp}$ mice (these bands were appeared in the control experiment; data not shown), the $63 \mathrm{kDa}$ band was not detected with TES101 (Fig. 2B). This result indicates that Ts4 has immunoreactivity against a different protein from TEX101 in the immature testicular extracts.

\section{Identification of the sexually immature testicular protein recognized by Ts4}

Attempts were then made to identify the $63 \mathrm{kDa}$ molecule detected in the testicular extracts from 1 to 29 dpp mice (Fig. 2A), using immunoprecipitation method combined with LC-MS/MS. After immunoprecipitation with Ts4 using the testicular WP fraction from $22 \mathrm{dpp}$ mice, we confirmed that Ts4 detected a $63 \mathrm{kDa}$ band in the precipitant (Fig. 2C, lane 1). The immunoprecipitant with Ts4 was separated by SDS-PAGE and visualized by silver. The four specific bands at apparent molecular masses of $67,63,61$, and $57 \mathrm{kDa}$ were observed among the Ts4-precipitated proteins (Fig. 2D, lane 1), but not in the control (Fig. 2D, lane 2). Subsequently, we analyzed the precipitated proteins using LC-MS/MS. The silver staining band at the apparent molecular mass of $67 \mathrm{kDa}$ (Fig. 2D, lane 1, band (a)) contained CD73 (UniProt accession number [UPN]-Q61503) and DPEP3 (UPN-Q9DA79) (Table 1). Furthermore, NUP62 (UPNQ63850) and DPEP3 were detected in the $63 \mathrm{kDa}$ band (Fig. 2D, lane 1, band (b), Table 1 and Supplementary Table 2). The $61 \mathrm{kDa}$ band (Fig. 2D, lane 1, band (c)) contained NUP58 (UPN-Q8R332) (Table 1), which forms a complex with NUP62 (Finlay et al. 1991). In the
$57 \mathrm{kDa}$ band (Fig. 2D, lane 1, band (d)), only keratins were detected (Table 1). These results suggest that Ts4 may directly bind to NUP62 and DPEP3 detected in the $63 \mathrm{kDa}$ band, whereas the CD73 observed in the $67 \mathrm{kDa}$ band may form complexes with Ts4-reactive molecules.

\section{Confirmation of the molecules identified by LC-MS/ MS analysis}

Next, we confirmed the results of the proteomic analysis using immunohistochemical and Western blot analyses. Among the proteins detected by LC-MS/MS, DPEP3 has already been identified as a protein that forms complexes with one of the Ts4-immunoreactive molecules, TEX101, in testicular germ cells at maturity (Yoshitake et al. 2011). The immunofluorescence study indicated immunoreactivity of anti-DPEP3 pAb with the plasma membrane of germ cells in testes from $22 \mathrm{dpp}$ mice, which was similar to the immunoreactivity of Ts4 (Supplementary Fig. 1A, B and C). Western blot analysis revealed that DPEP3 existed in theTs4 immunoprecipitant from testicular extracts of $22 \mathrm{dpp}$ mouse (Supplementary Fig. 1D, lane 1). However, since the anti-DPEP3 pAb used in this experiment is incompatible with the immunoprecipitation assay (Yoshitake et al. 2011), we could not independently confirm that DPEP3 was one of the Ts4-reactive molecules in 22 dpp testes.

Using Western blot analysis, we determined that NUP62 was present in the Ts4 immunoprecipitant from $22 \mathrm{dpp}$ mice testicular extracts (Fig. 3A, lane 1), but not in the normal control IgM-precipitated proteins (Fig. 3A, lane 2) or in the other controls (Fig. 3A, lanes 3 and 4). We examined whether Ts4 showed immunoreactivity

Table 1 LC-MS/MS analysis for confirmation of molecules immunoprecipitated with Ts4.

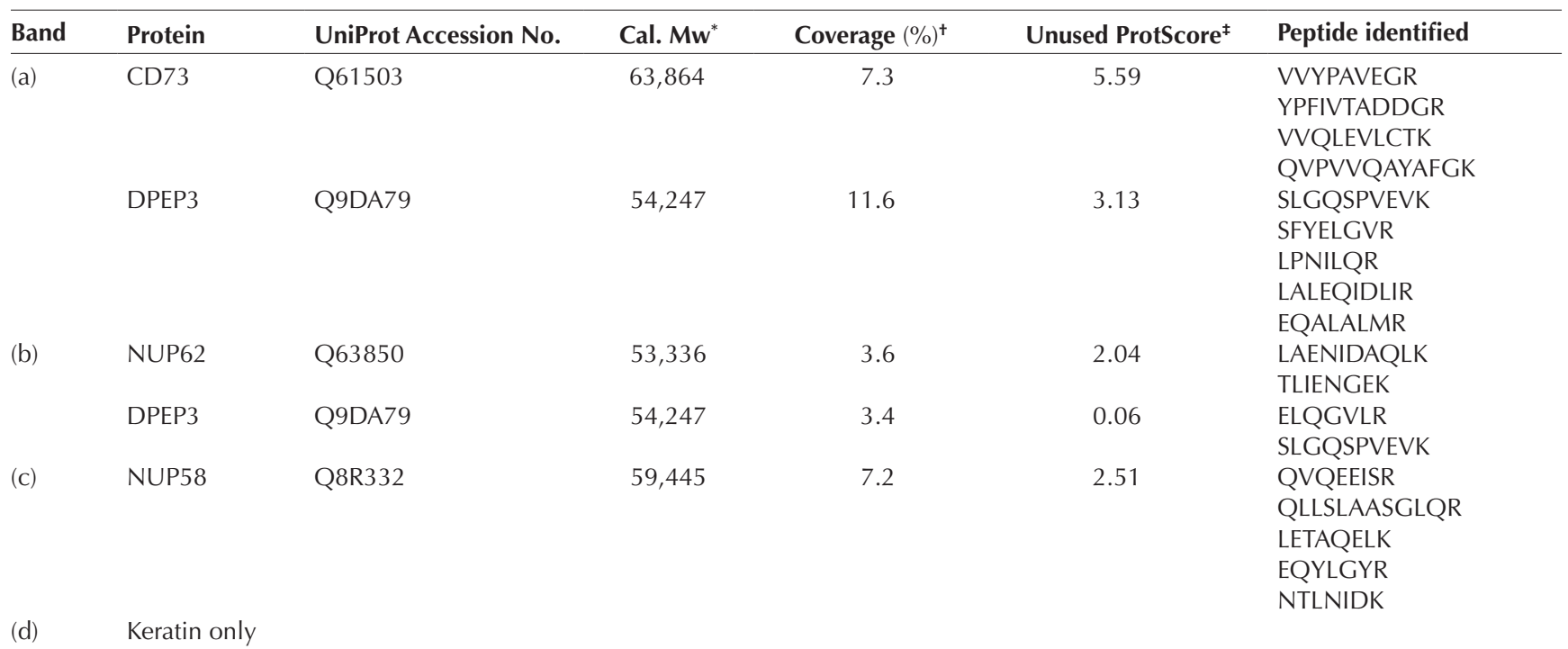

The results of the proteins only detected in the Ts4 immunoprecipitant are cited.

${ }^{*}$ Cal. Mw: Calculated molecular weight from primary protein sequence without posttranslational modifications. ${ }^{+}$Coverage $(\%)$ : The percentage of matching amino acids from identified peptides having confidence greater than 0 divided by the total number of amino acids in the sequence. * Unused ProtScore: A measure of the protein confidence for a detected protein, calculated from the peptide confidence for peptides from spectra that are not already completely 'used' by higher scoring winning proteins. The value was calculated by ProteinPilot 5.0.1 Software. 
against the immunoprecipitant identified with the antiNUP62 pAb. As expected, the specific $63 \mathrm{kDa}$ band was detected with either anti-NUP62 pAb or Ts4 in the immunoprecipitant (Fig. 3B, lanes 1 and 3). In addition, Western blot analysis of the Ts4 immunoprecipitant separated by $2 \mathrm{D}$ electrophoresis showed that the anti-NUP62 pAb detected a spot at the apparent pl/ molecular mass of $\mathrm{pl} 5 / 63 \mathrm{kDa}$, which merged with the spot observed using Ts4 (Fig. 3C, overlay).

We further investigated the localization of the Ts4reactive molecules and NUP62 within the testis from 22 dpp mouse using immunohistochemical analysis. However, the commercially available anti-NUP62 pAb in this study was incompatible with immunohistochemical applications (data not shown). As an alternative way to determine the subcellular localization of NUP62, the 22 dpp testes were extracted into EC, WS and TS fractions and subjected to Western blot analysis using anti-NUP62 pAb. The $63 \mathrm{kDa}$ band was detected in all the three fractions (Fig. 4, lanes 2-4), as well as in the WP fraction (Fig. 4, lane 1). The $63 \mathrm{kDa}$ band was also detected with Ts4 in the EC, WS and TS fractions (Fig. 4, lanes 6-8). In addition to the 63-kDa band, Ts4 recognized a $38 \mathrm{kDa}$ band (presumably corresponding to TEX101) (Fig. 4, lane 8), which was not detectable in the same amount of the WP fraction.
A

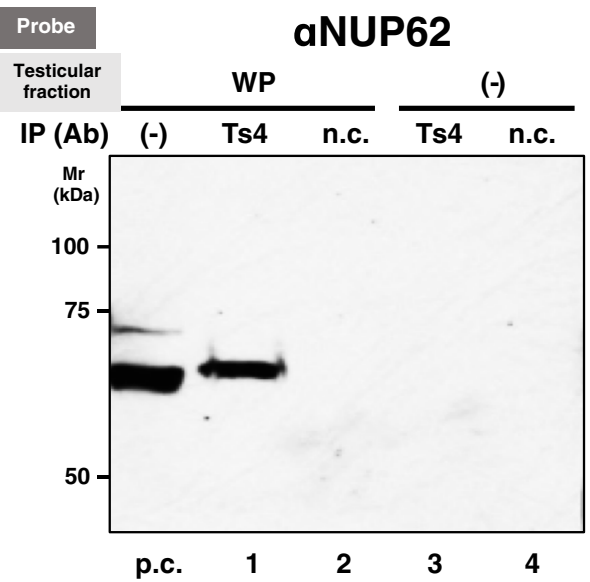

B

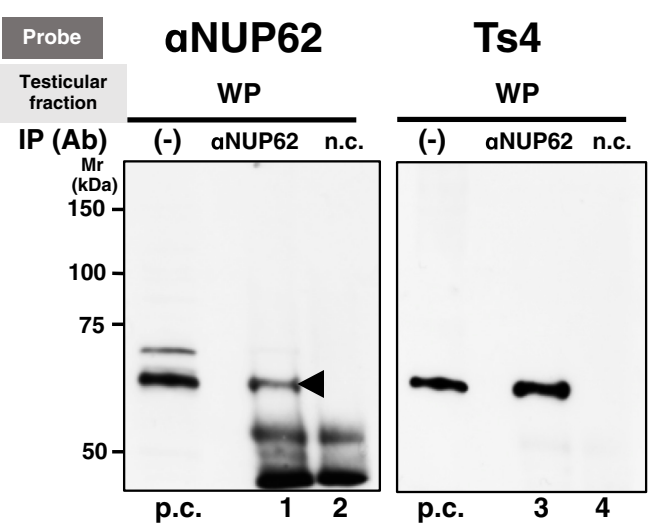

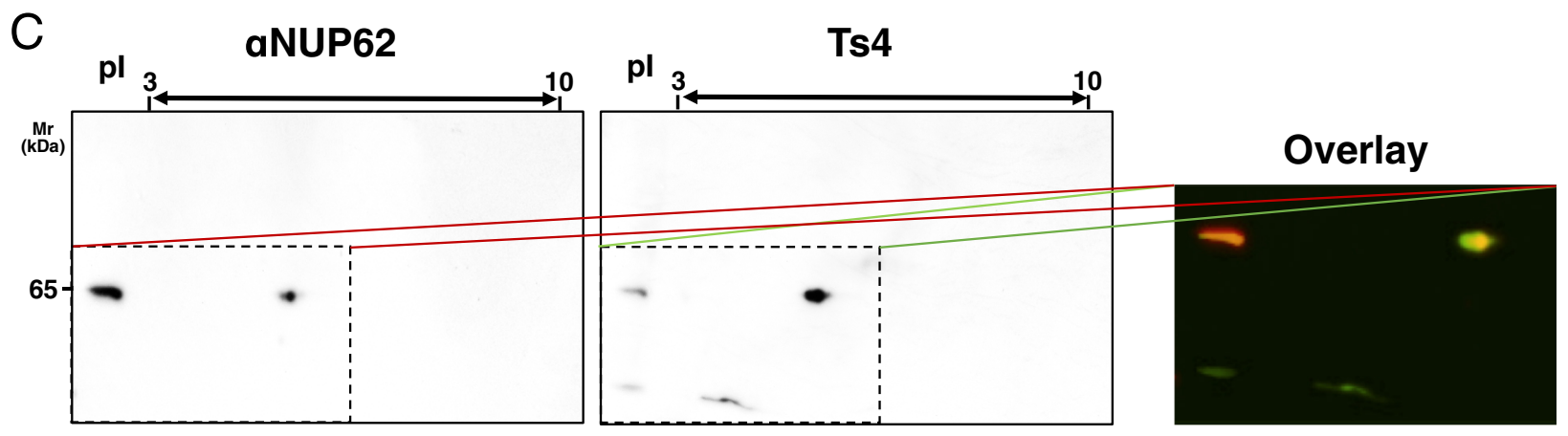

Figure 3 Relation between Ts4-recognized molecules and NUP62 in the testes from $22 \mathrm{dpp}$ mice. Western blot analyses of testicular proteins immunoprecipitated with Ts4 (A) or the anti-NUP62 pAb ( $\alpha$ NUP62) (B). Testicular WP fraction (20 $\mu$ g) (A and B, p.c.) and the immunoprecipitated proteins from the WP fraction with either Ts4 (A, lane 1) or RP-3 (n.c.) (A, lane 2), or either the $\alpha$ NUP62 (B, lanes 1 and 3 ) or negative control rabbit Ig (n.c.) (B, lanes 2 and 4 ) were applied to each lane of a $7.5 \%$ SDS-PAGE gel under reducing conditions and subjected to Western blot analysis using the $\alpha$ NUP62 (A; p.c., lanes 1, 2, B; p.c., lanes 1, 2) or Ts4 (B; p.c., lanes 3, 4). Other control experiments were conducted under the same conditions, except for the absence of the tissue extract (-) (A, lanes 3, 4). Arrowhead indicates the specific band detected with $\alpha$ NUP62. 2D electrophoresis of Ts4-immunoprecipitant followed by Western blot analysis using the $\alpha$ NUP62 and Ts4 (C). The immunoprecipitated protein from the WP fraction was applied to an IPGphor strip (7 cm; GE Healthcare Life Sciences) and IEF was performed at $\mathrm{pH}$ range from 3 to 10 . EF was performed as follows: Step and hold from 0 to $300 \mathrm{~V}$ over $30 \mathrm{~min}$, gradient from 300 to $1000 \mathrm{~V}$ over $30 \mathrm{~min}$, gradient from 1000 to $5000 \mathrm{~V}$ over $90 \mathrm{~min}$, and then hold at $5000 \mathrm{~V}$ for $36 \mathrm{~min}$. For the second dimension, the IPGphor strip was placed onto a stacking gel and subjected to $7.5 \%$ SDS-PAGE. Testicular WP protein $(20 \mu \mathrm{g})$ was applied to the left lane of the IPGphor strip for SDS-PAGE. Both the IEF and SDS-PAGE procedures were performed under reducing conditions. The separated proteins were transblotted onto a PVDF membrane, and then probed with $\alpha$ NUP62. After the specific spot was observed, the membrane was incubated with EzReprobe (ATTO Corporation, Tokyo, Japan) to strip the pAb from the membrane. The membrane was re-probed with Ts4. The images detected using the $\alpha$ NUP62 (red) and Ts4 (green) (within dotted lines) were overlaid using Adobe Photoshop Elements 7 (San Jose, CA, USA). Testicular WP fraction of $200 \mu \mathrm{g}$ and $15 \mu$ g of Abs were used for immunoprecipitation for Western blot analysis. 


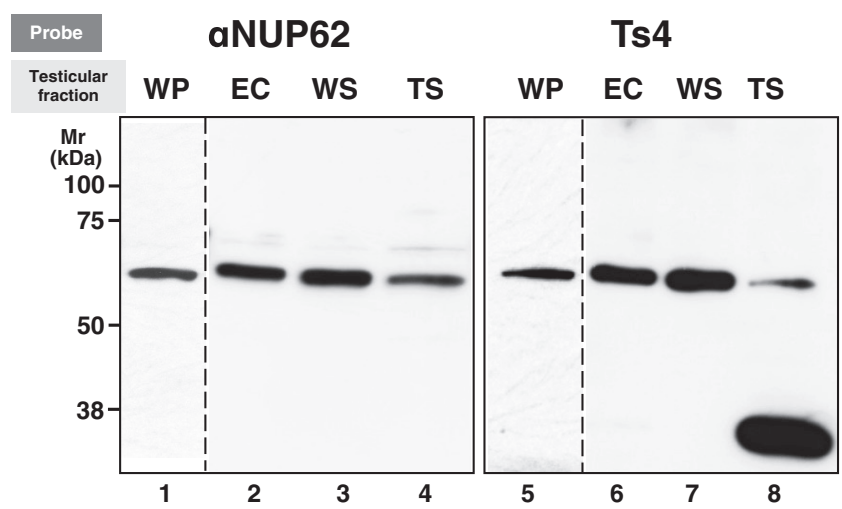

Figure 4 Expression of NUP62 in each fraction of 22 dpp mice testicular extract. Testicular proteins of the WP, EC, WS and TS fraction (each $20 \mu \mathrm{g}$ ) were applied to a $7.5 \%$ SDS-PAGE under reducing conditions, electroblotted onto PVDF membrane and then detected with anti-NUP62 pAb ( $\alpha$ NUP62) or Ts4.

\section{Relationship between CD73 and Ts4-reactive molecules in testicular germ cells at $22 \mathrm{dpp}$}

Concerning candidate molecules of Ts4-reactive proteins apart from NUP62, the immunofluorescence study showed that the anti-CD73 pAb was immunoreactive mainly with the plasma membrane of germ cells in testes from $22 \mathrm{dpp}$ mice (Supplementary Fig. 2B), which was similar to the Ts4 immunoreactivity pattern (Supplementary Fig. 2C). In addition, Western blot analysis revealed that CD73 existed in the Ts4 immunoprecipitant from $22 \mathrm{dpp}$ mice testicular extract (Supplementary Fig. 2D, lane 1), but not in the normal control IgM-precipitated proteins (Supplementary Fig. 2D, lane 2) or in the other controls (Supplementary Fig. 2D, lanes 3 and 4). Taking a bidirectional approach, we examined whether the immunoprecipitant obtained with the anti-CD73 pAb contained both CD73 itself and the molecules reactive to Ts4 in $22 \mathrm{dpp}$ mice testicular extract. The anti-CD73 pAb immunoprecipitant reacted with the same pAb (Supplementary Fig. 2E, lane 1), but not with Ts4 (Supplementary Fig. 2F, lane 1). This result suggested that although the $22 \mathrm{dpp}$ mice testicular immunoprecipitant with Ts4 contained CD73, it did not contain a detectable level of the Ts4-reactive molecules. These results led us to speculate that CD73 was a member of the molecular complexes containing the Ts4reactive molecules (e.g., TEX101 and NUP62), but was not a glycoprotein directly recognized by the mAb.

Next, we verified this hypothesis. Western blot analysis showed that the proteins immunoprecipitated with TES101 (an anti-TEX101 mAb, compatible for immunoprecipitation) were recognized by 6035 (a mAb specific to the peptide portion of TEX101 (Yoshitake et al. 2008a)) (Supplementary Fig. 3, lane 1), Ts4 (Supplementary Fig. 3, lane 3), the anti-CD73 pAb (Supplementary Fig. 3, lane 5) and the anti-DPEP3 (Supplementary Fig. 3, lane 9), but not by the anti-
NUP62 pAb (Supplementary Fig. 3, lane 7). These results indicate that CD73 forms a complex with TEX101 and DPEP3 (one of the molecules associated with TEX101 (Yoshitake et al. 2011)), but not with NUP62 in the 22 dpp testis.

\section{Characterization of Ts4-reactive OS chain modified to NUP62 in 22 dpp testis}

We previously reported that the reactivity of Ts4 against TEX101 in the adult testis vanished after digestion with $\mathrm{N}$-glycanase (an endoglycosidase that releases intact $\mathrm{N}$-glycans from glycoproteins by cleaving between the innermost GlcNAc and asparagine residue of $N$-glycosylation sites (Tarentino et al. 1985)) and $\beta-N$ acetylglucosaminidase (a highly specific exoglycosidase that catalyzes the hydrolysis of terminal non-reducing GlcNAc residues) (Wong-Madden \& Landry 1995, Yoshitake et al. 2015). Next, we investigated whether these enzymes also abolished the Ts4 reactivity in the 22 dpp testis using Western blot analysis. Unexpectedly, treatment of the 22 dpp testicular extract with $\mathrm{N}$-glycanase did not change the reactivity of Ts4 (Fig. 5A, lanes 1 and 2) or the anti-NUP62 pAb (Fig. 5A, lanes 3 and 4). However, the size of band recognized by the anti-CD73 pAb decreased from $67 \mathrm{kDa}$ to $58 \mathrm{kDa}$ after digestion with $\mathrm{N}$-glycanase (Fig. 5A, lanes 5,6). This result suggests that the Ts4-reactive OS chain on NUP62 in the 22 dpp testis did not possess the sensitivity to $\mathrm{N}$-glycanase, unlike TEX101 in the adult testis. We also examined the effect of $\beta$-N-acetylglucosaminidase on the same OS chain. The $63 \mathrm{kDa}$ band detected with Ts4 was completely abrogated after $\beta$ - $N$-acetylglucosaminidase treatment (Fig. 5B, lanes 1,2). Furthermore, the same treatment caused a size reduction of the band recognized by the anti-NUP62 pAb from $63 \mathrm{kDa}$ to $59 \mathrm{kDa}$ (and faintly 55 kDa) (Fig. 5B, lanes 3,4). Under the same conditions, no change in the mobility of the anti-CD73 pAb was observed (Fig. 5B, lanes 5, 6). Collectively, these results indicate that the Ts4-reactive OS chain on NUP62 in the 22 dpp testis contains terminal GlcNAc residues.

In addition, we compared the immunoreactivity of both Ts4 and anti-NUP62 antibody against testicular WP from $1 \mathrm{dpp}$ to $29 \mathrm{dpp}$ (Fig. 6A). During testicular development after birth, Ts4 immunoreactivity is gradually increased from $1 \mathrm{dpp}$ to $22 \mathrm{dpp}$ and then decreased at $29 \mathrm{dpp}$, whereas NUP62 expression increased in parallel with the term after birth (Fig. 6B). These results suggest that the bisecting GlcNAc modification on NUP62 is regulated in the developmental stage.

\section{Expression of NUP62 and CD73 in the testis of sexually mature mouse}

We reported that Ts4 reacts with various kinds of proteins in the adult testis, especially the WS fraction (Yoshitake et al. 2008a). Next, we examined whether 
A Probe

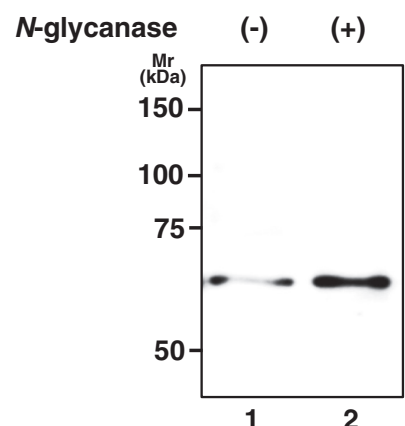

B

Probe

$\beta$-N-acetylglucosaminidase $\mathrm{Mr}$

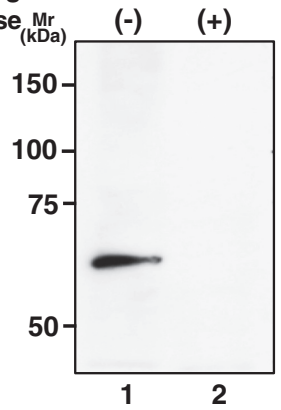

aNUP62

$(-) \quad(+)$

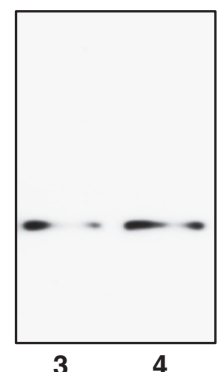

aNUP62
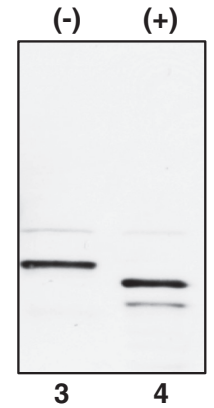

aCD73

$(-) \quad(+)$

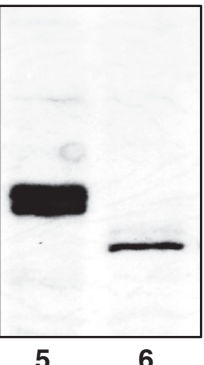

aCD73

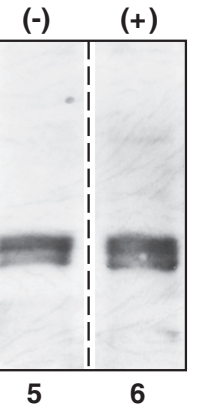

Figure 5 Glycosylation pattern of the Ts4-reactive molecules in the 22 dpp testis. Western blot analysis of the WP fraction after $\mathrm{N}$-glycanase (A) or $\beta$ - $N$-acetylglucosaminidase (B) digestion. Testicular WP fraction $(200 \mu \mathrm{g})$ was incubated at $37^{\circ} \mathrm{C}$ for $24 \mathrm{~h}$ with/ without $5 \mathrm{mU}$ of $\mathrm{N}$-glycanase $(100 \mathrm{mU} / 40 \mu \mathrm{L})$ (ProZyme Inc., San Leandro, CA, USA) in a total volume of $50 \mu \mathrm{L}$ or for $1 \mathrm{~h}$ with/without $20 \mathrm{U}$ of $\beta$ - $N$-acetylglucosaminidase $(4000 \mathrm{U} / \mathrm{mL})$ (New England Biolabs Inc., Ipswich, MA, USA) in a total volume of $15 \mu \mathrm{L}$. These samples containing $20 \mu \mathrm{g}$ of substrates were applied and separated by a $7.5 \%$ SDS-PAGE gel under reducing conditions, electroblotted onto PVDF membrane, and then detected with Ts4, anti-NUP62 ( $\alpha$ NUP62) or anti-CD73 $(\alpha C D 73)$ pAbs. After pull down using PHA-E, the solubilized proteins from the WP fraction were applied and separated by a $7.5 \%$ SDS-PAGE gel under reducing conditions, electroblotted onto PVDF membrane, and then detected with the $\alpha$ NUP62 or Ts4 (C) (lanes 2,4$)$. Testicular WP fraction $(20 \mu \mathrm{g})$ was applied as positive control (p.c.) (lanes 1,3).

NUP62 is expressed as a Ts4-reactive molecule in the adult testis, as well as in the sexually developing testis. Western blot analysis showed that $63 \mathrm{kDa}$ bands were detected with both Ts4 and the anti-NUP62 pAb in the Ts4-immunoprecipitated testicular WS fraction of 8-week-old mouse (Fig. 7A), suggesting that NUP62 exists in the sexually mature testis while possessing the Ts4-reactive OS chain. We further found that CD73 was also associated with TEX101 in the adult testis (Fig. 7B).

\section{Discussion}

In the present study, we demonstrated for the first time, that Ts4 exhibits immunoreactivity against the immature

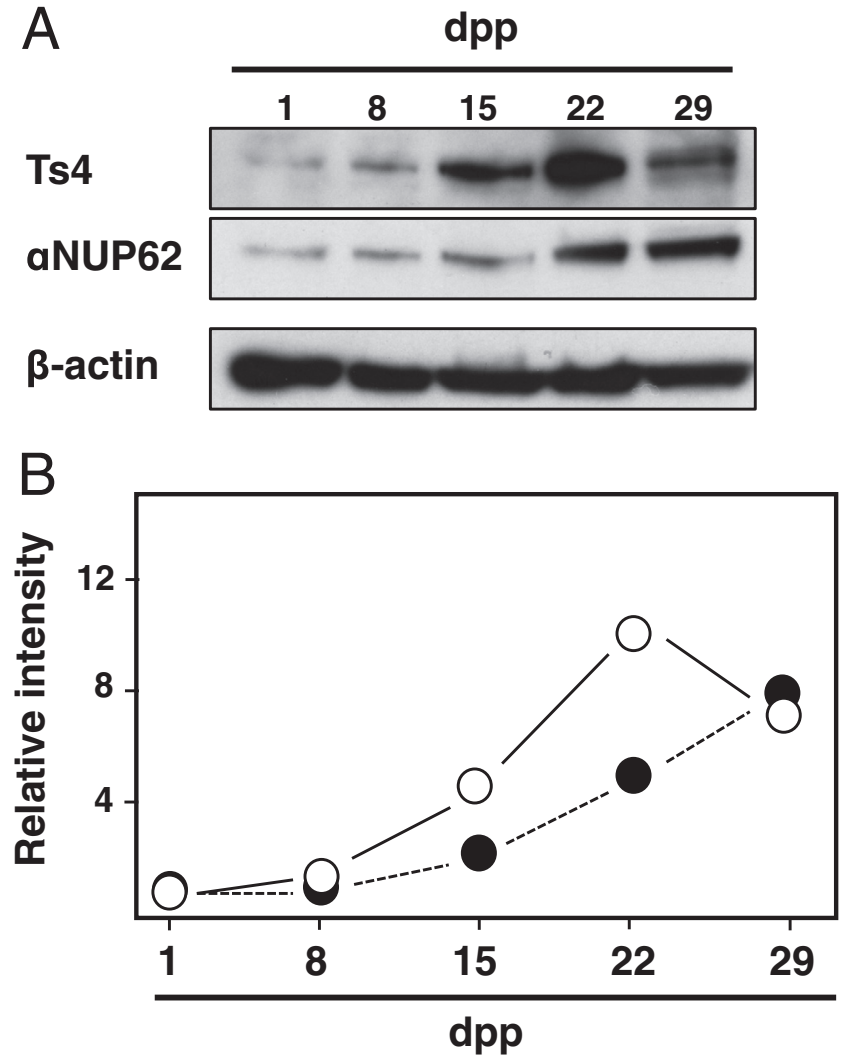

Figure 6 Comparison of expression profile between NUP62 and Ts4 reactive sugar residues on NUP62. Western blot analysis with Ts4 or anti-NUP62 pAb ( $\alpha$ NUP62) during testicular development (A). Testicular WP fractions of 1, 8, 15, 22, and 29 dpp were applied to a $7.5 \%$ SDS-PAGE under reducing conditions, electroblotted onto PVDF membrane, and then detected with either Ts4 or $\alpha$ NUP62. Expression of $\beta$-actin was used as a quantitative internal control. Densitometry analyses of immunopositive (B). The relative signal intensity for Ts4 (open circle) or $\alpha$ NUP62 (closed circle) in panel A are plotted. The immunoreactive density of Ts4 signal from $1 \mathrm{dpp}$ testis was expressed as basic relative value $(=1)$.

mouse testis. However, the pattern of Ts4 reactivity was different from that of the adult testis (Figs 1 and 2). Our previous immunohistochemical analysis of the mature testis showed that Ts4 reactivity was observed mainly on the plasma membrane of germ cells (Yoshitake et al. 2008a, Shirai et al. 2009), indicating that the Ts4recognized OS chain binds to membrane glycoproteins. Indeed, TEX101 expressed on cell surfaces as a glycosylphosphatidylinositol-anchored protein (GPI-AP) (Jin et al. 2006) was identified as one of the molecules modified by the Ts4-reactive bisected $\mathrm{N}$-glycan in the mature testis (Yoshitake et al. 2008a). Conversely, positive signals in the testes were found on the nuclear membrane from $14 \mathrm{dpc}$ to $8 \mathrm{dpp}$, in the cytoplasm at $15 \mathrm{dpp}$, and mainly on the plasma membrane/faintly in the cytoplasm of germ cells at $22 \mathrm{dpp}$ (Fig. 1A, B, C, D, E and F). In addition, we showed using Western blot analysis that Ts4 binds to the $63 \mathrm{kDa}$ molecule, a different molecule from TEX101, in the immature 
A
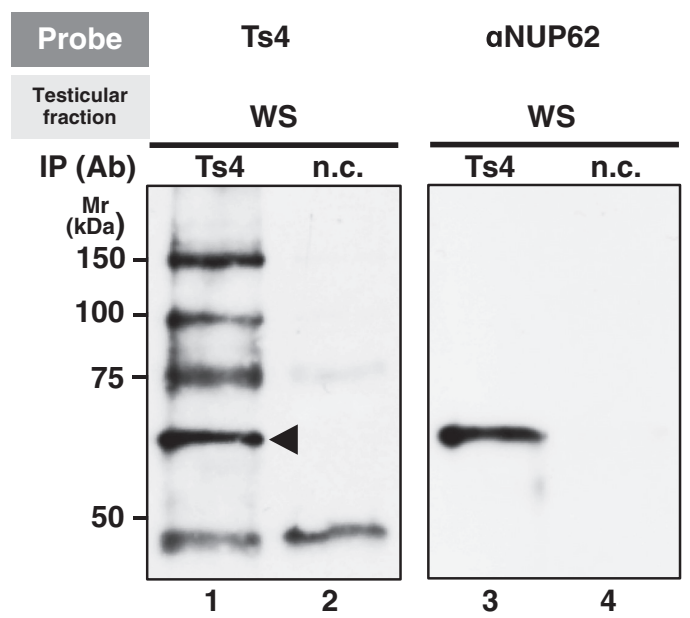

B

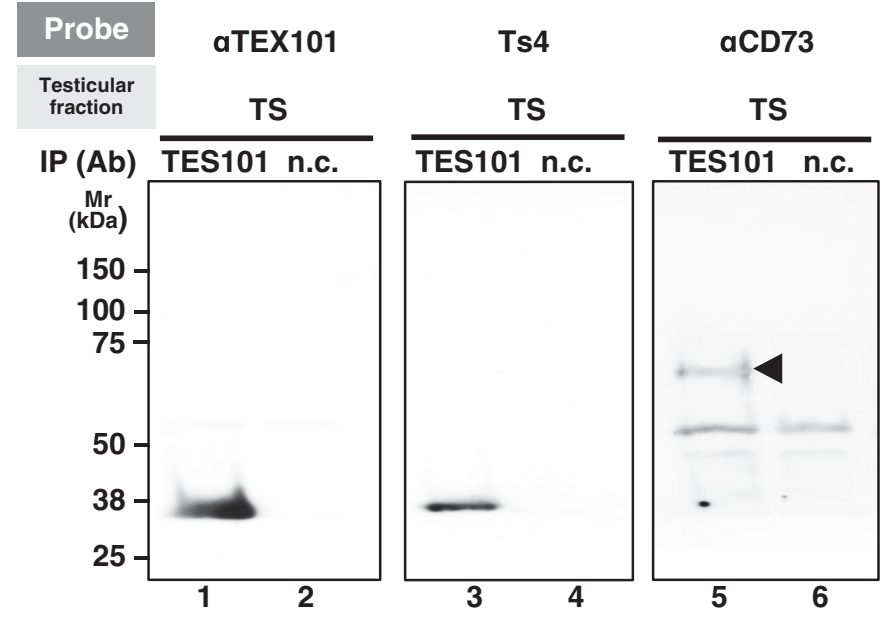

Figure 7 Expression of the Ts4-related molecules in the adult testis. Reactivity of the anti-NUP62 pAb ( $\alpha$ NUP62) against the Ts4 immunoprecipitant (A). Immunoprecipitants (IP) using $100 \mu \mathrm{g}$ of WS fraction from 8-week-old mice with $15 \mu \mathrm{g}$ of either Ts4 (lanes 1, 3) or RP-3 (n.c.) (lanes 2,4) were applied and separated by a 7.5\% SDS-PAGE gel under reducing conditions, electroblotted onto PVDF membrane, and then detected with Ts4 or $\alpha$ NUP62. Relation between TEX101 and CD73 (B). IP using $50 \mu g$ of TS fraction and $7.5 \mu \mathrm{g}$ of either TES101 (a mAb, compatible for immunoprecipitation) (lanes 1, 3, 5) or 3H9 (n.c.) (lanes 2, 4, 6) were applied and separated by a 10\% SDS-PAGE gel under reducing conditions, electroblotted onto PVDF membrane, and then detected with 6035 ( $\alpha$ TEX101), Ts4 or anti-CD73 pAb ( $\alpha C D 73$ ). Arrowhead indicates the specific band detected with each $\mathrm{Ab}$.

testes from mice before 29 dpp (Fig. 2). After 29 dpp, Ts4 exhibits reactivity against several glycoproteins, including TEX101. We previously reported that Naglu was recognized with the $\mathrm{mAb}$ in the epididymal spermatozoa (Yoshitake et al. 2016). Therefore, these previous and present results indicate that the molecules possessing Ts4-reactive bisecting GlcNAc change in male germ cells during its differentiation and maturation. Using an immunoprecipitation method combined with liquid LC-MS/MS, we identified DPEP3, CD73, and NUP62 as potential glycoproteins modified with the Ts4-recognized bisected $\mathrm{N}$-glycan in the immature testis (Table 1 and Supplementary Table 2).

DPEP3 belongs to the membrane-bound dipeptidase family (Habib et al. 1998), which has an enzymatic activity for the conversion of leukotriene D4 to leukotriene E4 or the cleavage of cystinyl-bis-glycine (Habib et al. 2003). Expression of DPEP3 is observed only in the testis (Habib et al. 2003); however, its biological function in vivo remains unclear, although a recent study reported that Dpep3-deficient mouse is fertile (Xie et al. 2019). We previously reported that DPEP3 was not directly recognized by Ts4 in the mature testis, but that TEX101 was physically associated with DPEP3 (Yoshitake et al. 2011). The present study indicates that CD73 also forms a complex with TEX101 in $22 \mathrm{dpp}$ and adult testes (Supplementary Fig. 3), but not possesses Ts4-reactive OS chain (Supplementary Figs 2 and 3). CD73, otherwise known as ecto-5'nucleotidase, is an enzyme that dephosphorylates extracellular adenosine $5^{\prime}$-monophosphate (AMP) into adenosine via a purinergic signaling pathway (Zimmermann et al. 2012, Regateiro et al. 2013). CD73 expression is widely observed in various tissues, such as the brain, heart, lung, liver, kidney, colon, and placenta (Resta et al. 1993, Thompson et al. 2004), as well as some types of leukocytes, including T cells, neutrophils, monocytes/macrophages, and dendritic cells (Antonioli et al. 2013). The expression of CD73 in the testis has also been reported previously (Martin-Satue et al. 2010). Concerning CD73 and adenosine in general, many studies have reported that both molecules are key modulators for suppression of the immune response in the tumor microenvironment (Stagg \& Smyth 2010, Salmi \& Jalkanen 2012, Stagg 2012, Zhang 2012). Interestingly, CD73 exists on cell surfaces as a GPI-AP (Antonioli et al. 2013), as do several other molecules related to Ts4, including TEX101, DPEP3, and Ly6k (Jin et al. 2006, Yoshitake et al. 2008b, 2011). At present, GPIAPs are believed to exist on membrane microdomains (known as lipid rafts) containing abundant cholesterol, sphingolipids, and Src-family kinases (Lingwood \& Simons 2010). A recent report suggested that each GPI-AP possessing complex and high mannose type of $\mathrm{N}$-glycans forms a specific lipid raft (MiyagawaYamaguchi et al. 2015). The molecules associated with TEX101, including CD73, create cluster formations in the same lipid raft, and may belong to the molecular group configuring the lipid raft on germ cells in testis.

Among the candidate molecules targeted by Ts4 (Table 1 and Supplementary Table 2), data obtained from the present study clearly demonstrated NUP62 
as a glycoprotein in immature testis possessing a Ts4 reactive OS chain (Fig. 3). NUP62 was first identified as a component of nuclear pore complexes (NPC) with roles in nucleocytoplasmic transport. This molecule is reported to localize outside the NPC and to be involved in a wide variety of processes apparently unrelated to NPC function, including microtubule regulation in the cytoplasm, centromere and kinetochore function in mitosis, spindle assembly, and cell migration (Yang et al. 2006, Hubert et al. 2009, Hashizume et al. 2013). Unfortunately, the anti-NUP62 pAb used in the present study was incompatible with immunohistochemistry. However, NUP62 is reported to be expressed in the cytoplasm and nucleus of germ cells (Whiley et al. 2012).

Although our experimental results allow us to conclude that NUP62 is the Ts4-reactive glycoprotein in the immature testis, the amino acid sequence of mouse NUP62 does not have the typical consensus sequence for $\mathrm{N}$-glycosylation, which is asparagine- $\mathrm{X}$ (X may be any amino acid other than proline)-serine/ threonine (Marshall 1974). In addition to the consensus sequence, atypical motifs for glycosylation have also been reported, including asparagine-X-cysteine (Stenflo \& Fernlund 1982, Sun \& Zhang 2015, Lowenthal et al. 2016), asparagine-X-valine (Sun \& Zhang 2015), asparagine-X-glycine (Valliere-Douglass et al. 2009), serine/threonine-X-asparagine and glutamine-glycinethreonine (Valliere-Douglass et al. 2010). Mouse NUP62 has amino acid motifs for the above sequences (asparagine-X-glycine, five sites; serine/threonine- $X$ asparagine; two sites, glutamine-glycine-threonine; two sites); therefore, the resistance to $\mathrm{N}$-glycanase in Ts4reactive OS chain in $22 \mathrm{dpp}$ immature testes may be due to an atypical attachment of the OS chain.

We reported that Ts4 exhibits similar reactivity to embryonic stem (ES) cells in immature testes (Shirai et al. 2009). Indeed, the shifting distribution of Ts4 reactivity from the nuclear membrane to cytoplasm in the developing testes (Fig. 1A, B, C, D, E and F) is consistent with the previously reported distribution of Ts4 reactivity in the early embryo (Shirai et al. 2009).

The reactivity of Ts4 and molecules associated with the $\mathrm{mAb}$ during testicular development are summarized in Fig. 8. In ES cells, NUP62, CD73, DPEP3, and Ly6k

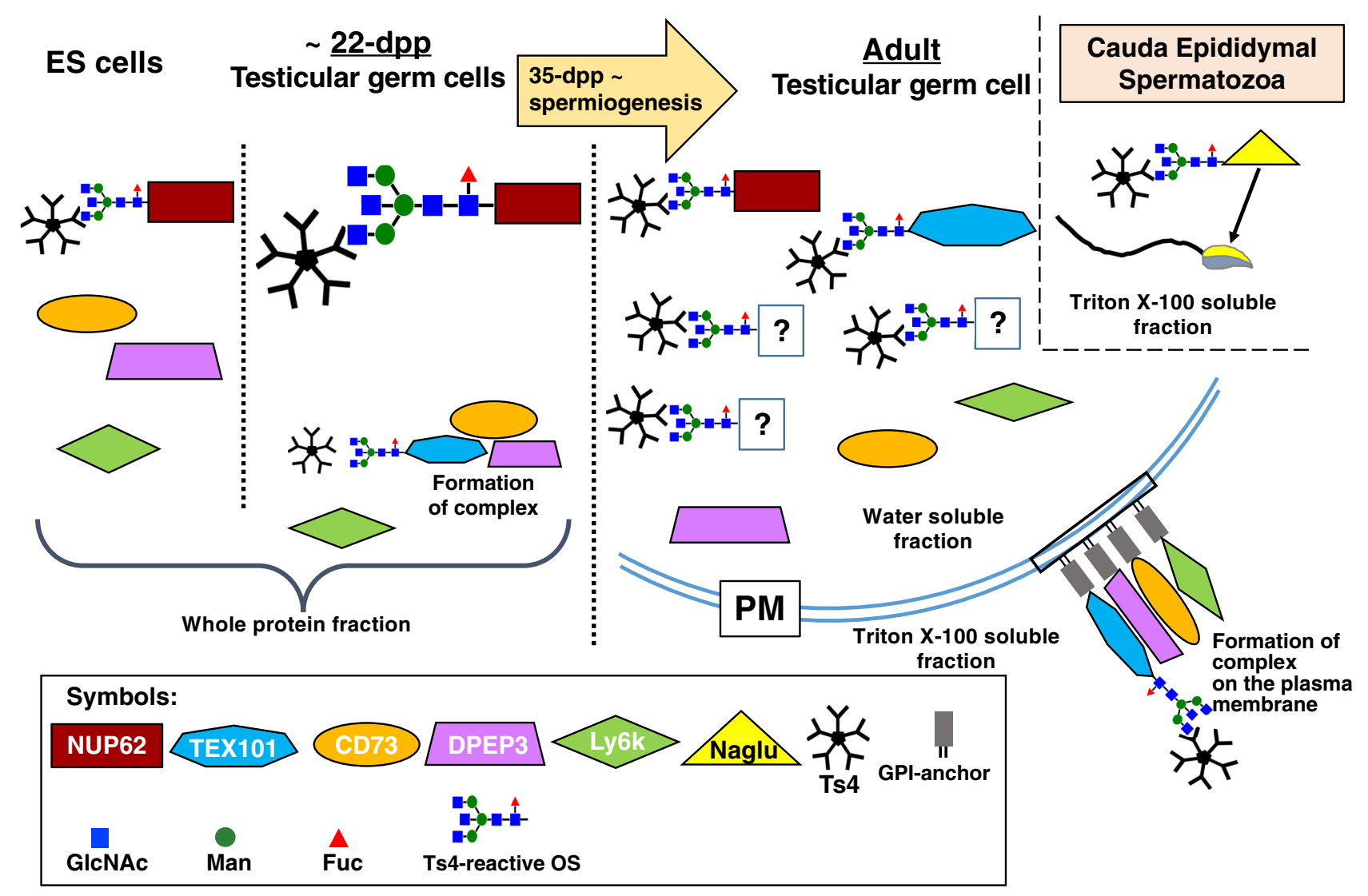

Figure 8 Molecular status of molecules related to Ts4 reactive OS chains during development. In the ES cells, Ts4-reactive OS chain detection is limited to NUP62. During testicular development after birth around by $22 \mathrm{dpp}$, the OS chain is mainly detected on NUP62, and a trace amount was detected on TEX101 which forms complex with CD73 and DPEP3 (not with Ly6k) in the testicular germ cells. After the initiation of spermiogenesis, several testicular proteins including NUP62 possess the Ts4-reactive OS chain in the germ cells; however, TEX101 forms molecular complex with CD73, DPEP3, and Ly6k on the plasma membrane (PM) of germ cells. Fuc, fucose; GlcNAc, N-acetylglucosamine; GPI, glycosylphosphatidylinositol; Man, mannose; Naglu, alpha-N-acetylglucosaminidase; OS, oligosaccharide. 
were detected using Western blot analysis (data not shown); however, as previously reported, TEX101 was not detectable (Shirai et al. 2009). ES cells possess a Ts4-reactive OS chain on NUP62 (Supplementary Fig. 4). In immature testicular germ cells, experiments were performed using the WP fraction, which demonstrated the complex formation of TEX101, CD73 and DPEP3. Ly6k, a molecule which forms complex with TEX101 in adult testis (Yoshitake et al. 2008b), is also expressed in 22-dpp testis; however, it was not detectable in antiTEX101 pAb-immunoprecipitant using Western blot analysis (data not shown). Although TEX101 possesses a Ts4-reactive OS chain, the predominant molecule possessing a Ts4-reactive OS chain was determined to be NUP62. After $29 \mathrm{dpp}$, Ts4 exhibits reactivity against several molecules (Fig. 2A). In adult testis, NUP62, TEX101 and other unknown molecules possess Ts4reactive OS chains in the WS fraction. CD73, DPEP3, and Ly6k were detected in the WS fraction. However, based on Western blot analysis they do not seem to form complexes in this fraction (data not shown). Using the TS fraction, we showed in the present study that CD73 forms a complex with TEX101 (Fig. 7), and previously reported that TEX101 also forms complexes with DPEP3 and Ly6k (Yoshitake et al. 2008b, 2011). In cauda epididymal spermatozoa, the Ts4-reactive OS chain is shifted to locate on Naglu (Yoshitake et al. 2016).

In summary, we demonstrated that Ts4-reactive molecules changed around $35 \mathrm{dpp}$ and that NUP62 is the predominant molecule possessing Ts4-reactive bisecting GlcNAc in testis during sexual development. This study provided additional information on the biochemical characteristics of glycoproteins carrying bisecting GlcNAc in relation to mammalian reproductive development. Although we do not yet have direct evidence concerning whether this OS chain detected by Ts4 has biological significance, the experimental results of the present study would contribute to our understanding of the regulation of the early development of testicular germ cells.

\section{Supplementary data}

This is linked to the online version of the paper at https://doi.org/10.1530/REP-19-0333.

\section{Declaration of interest}

The authors declare that there is no conflict of interest that could be perceived as prejudicing the impartiality of the research reported.

\section{Funding}

This work was supported in part by Grants-in-Aid for General Scientific Research Nos. 25462575/17K19734/18KK0256
(Y A), $26293358(\mathrm{H} \mathrm{F}), 16 \mathrm{~K} 11111(\mathrm{H} \mathrm{Y})$ from the Minister of Education, Culture, Sports, Science \& Technology, Japan, grants from AMED, Nos. 17gk0110024h0001/17cm0106X XXh0001 (H F), and Juntendo University Young Investigator Joint Project Award (R O-S).

\section{Author contribution statement}

R O-S conceived and designed the study, collected data, performed data analysis and interpretation, provided financial support and wrote the article. HY designed and supervised the study, provided financial support and wrote the article. S K, Y $\mathrm{M}, \mathrm{K} \mathrm{Y}$ and $\mathrm{T} U$ collected data and performed data analysis and interpretation. $\mathrm{K} \mathrm{T}, \mathrm{A} \mathrm{H}, \mathrm{A} \mathrm{I}, \mathrm{H} \mathrm{F}$ and S T analyzed the data, provided financial supports. Y A conceived, designed and directed the study, provided financial support and wrote the article. All authors have given approval to the final version of the article.

\section{Acknowledgements}

The excellent assistance of Dr Masaru Kurosawa and Ryota Kosuge (Experimental Animal Center, Juntendo University) is gratefully acknowledged. The authors are indebted to $\mathrm{Dr}$ Yoichi Shinkai (RIKEN, Saitama, Japan) for his kind assistance.

This research was presented in part at the 51st Annual Meeting of the Society for the Study of Reproduction, 10-13 July 2018, New Orleans, Louisiana, USA

\section{References}

Antonioli L, Pacher P, Vizi ES \& Hasko G 2013 CD39 and CD73 in immunity and inflammation. Trends in Molecular Medicine 19 355-367. (https://doi.org/10.1016/j.molmed.2013.03.005)

Defaus S, Aviles M, Andreu D \& Gutierrez-Gallego R 2016 Identification of bovine sperm surface proteins involved in carbohydrate-mediated fertilization interactions. Molecular and Cellular Proteomics 15 22362251. (https://doi.org/10.1074/mcp.M115.057703)

Diekman AB 2003 Glycoconjugates in sperm function and gamete interactions: how much sugar does it take to sweet-talk the egg? Cellular and Molecular Life Sciences 60 298-308. (https://doi.org/10.1007/s000180300025)

Finlay DR, Meier E, Bradley P, Horecka J \& Forbes DJ 1991 A complex of nuclear pore proteins required for pore function. Journal of Cell Biology 114 169-183. (https://doi.org/10.1083/jcb.114.1.169)

Fujihara Y, Tokuhiro K, Muro Y, Kondoh G, Araki Y, Ikawa M \& Okabe M 2013 Expression of TEX101, regulated by ACE, is essential for the production of fertile mouse spermatozoa. PNAS 110 8111-8116. (https://doi.org/10.1073/pnas.1222166110)

Habib GM, Shi ZZ, Cuevas AA, Guo Q, Matzuk MM \& Lieberman MW 1998 Leukotriene D4 and cystinyl-bis-glycine metabolism in membranebound dipeptidase-deficient mice. PNAS 95 4859-4863. (https://doi. org/10.1073/pnas.95.9.4859)

Habib GM, Shi ZZ, Cuevas AA \& Lieberman MW 2003 Identification of two additional members of the membrane-bound dipeptidase family. FASEB Journal 17 1313-1315. (https://doi.org/10.1096/fj.02-0899fje)

Hashizume C, Moyori A, Kobayashi A, Yamakoshi N, Endo A \& Wong RW 2013 Nucleoporin Nup62 maintains centrosome homeostasis. Cell Cycle 12 3804-3816. (https://doi.org/10.4161/cc.26671)

Hubert T, Vandekerckhove J \& Gettemans J 2009 Exo70-mediated recruitment of nucleoporin Nup62 at the leading edge of migrating cells is required for cell migration. Traffic 10 1257-1271. (https://doi. org/10.1111/j.1600-0854.2009.00940.x)

Isaji T, Gu J, Nishiuchi R, Zhao Y, Takahashi M, Miyoshi E, Honke K, Sekiguchi K \& Taniguchi N 2004 Introduction of bisecting GlcNAc 
into integrin alpha5beta1 reduces ligand binding and down-regulates cell adhesion and cell migration. Journal of Biological Chemistry 279 19747-19754. (https://doi.org/10.1074/jbc.M311627200)

Jin H, Yoshitake H, Tsukamoto H, Takahashi M, Mori M, Takizawa T, Takamori K, Ogawa H, Kinoshita K \& Araki Y 2006 Molecular characterization of a germ-cell-specific antigen, TEX101, from mouse testis. Zygote 14 201-208. (https://doi.org/10.1017/ S0967199406003753)

Kitada T, Miyoshi E, Noda K, Higashiyama S, Ihara H, Matsuura N, Hayashi N, Kawata S, Matsuzawa Y \& Taniguchi N 2001 The addition of bisecting $\mathrm{N}$-acetylglucosamine residues to $\mathrm{E}$-cadherin down-regulates the tyrosine phosphorylation of beta-catenin. Journal of Biological Chemistry 276 475-480. (https://doi.org/10.1074/jbc.M006689200)

Kurita A, Takizawa T, Takayama T, Totsukawa K, Matsubara S, Shibahara H, Orgebin-Crist MC, Sendo F, Shinkai Y \& Araki Y 2001 Identification, cloning, and initial characterization of a novel mouse testicular germ cell-specific antigen. Biology of Reproduction 64 935-945. (https://doi. org/10.1095/biolreprod64.3.935)

Lee MC \& Damjanov I 1985 Lectin binding sites on human sperm and spermatogenic cells. Anatomical Record 212 282-287.

Lingwood D \& Simons K 2010 Lipid rafts as a membrane-organizing principle. Science 327 46-50. (https://doi.org/10.1126/science.1174621)

Lowenthal MS, Davis KS, Formolo T, Kilpatrick LE \& Phinney KW 2016 Identification of novel $\mathrm{N}$-glycosylation sites at noncanonical protein consensus motifs. Journal of Proteome Research 15 2087-2101. (https:// doi.org/10.1021/acs.jproteome.5b00733)

Marshall RD 1974 The nature and metabolism of the carbohydrate-peptide linkages of glycoproteins. Biochemical Society Symposium 17-26.

Martin-Satue M, Lavoie EG, Fausther M, Lecka J, Aliagas E, Kukulski F \& Sevigny J 2010 High expression and activity of ecto-5'-nucleotidase/ CD73 in the male murine reproductive tract. Histochemistry and Cell Biology 133 659-668. (https://doi.org/10.1007/s00418-010-0704-z)

Miyagawa-Yamaguchi A, Kotani N \& Honke K 2015 Each GPI-anchored protein species forms a specific lipid raft depending on its GPI attachment signal. Glycoconjugate Journal 32 531-540. (https://doi.org/10.1007/ s10719-015-9595-5)

Narasimhan R, Bennick A, Palmer B \& Murray RK 1982 Studies on the glycolipids of human saliva and gastric juice. Journal of Biological Chemistry 257 15122-15128.

Narasimhan S, Freed JC \& Schachter H 1986 The effect of a 'bisecting' $\mathrm{N}$-acetylglucosaminyl group on the binding of biantennary, complex oligosaccharides to concanavalin A, Phaseolus vulgaris erythroagglutinin (E-PHA), and Ricinus communis agglutinin (RCA-120) immobilized on agarose. Carbohydrate Research 149 65-83. (https://doi.org/10.1016/ s0008-6215(00)90370-7)

Noce T, Okamoto-Ito S \& Tsunekawa N 2001 Vasa homolog genes in mammalian germ cell development. Cell Structure and Function 26 131-136. (https://doi.org/10.1247/csf.26.131)

Rebbaa A, Yamamoto H, Saito T, Meuillet E, Kim P, Kersey DS, Bremer EG, Taniguchi N \& Moskal JR 1997 Gene transfectionmediated overexpression of beta1,4-N-acetylglucosamine bisecting oligosaccharides in glioma cell line U373 MG inhibits epidermal growth factor receptor function. Journal of Biological Chemistry 272 9275-9279. (https://doi.org/10.1074/jbc.272.14.9275)

Regateiro FS, Cobbold SP \& Waldmann H 2013 CD73 and adenosine generation in the creation of regulatory microenvironments. Clinical and Experimental Immunology $\mathbf{1 7 1} 1$ 1-7. (https://doi.org/10.1111/j.13652249.2012.04623.x)

Resta R, Hooker SW, Hansen KR, Laurent AB, Park JL, Blackburn MR, Knudsen TB \& Thompson LF 1993 Murine ecto-5'-nucleotidase (CD73): cDNA cloning and tissue distribution. Gene 133 171-177. (https://doi. org/10.1016/0378-1119(93)90635-g)

Salmi M \& Jalkanen S 2012 Host CD73 impairs anti-tumor immunity. Oncoimmunology 1 247-248. (https://doi.org/10.4161/onci.1.2.18310)

Sekiya S, Gotoh S, Yamashita T, Watanabe T, Saitoh S \& Sendo F 1989 Selective depletion of rat neutrophils by in vivo administration of a monoclonal antibody. Journal of Leukocyte Biology 46 96-102. (https:// doi.org/10.1002/jlb.46.2.96)

Shirai Y, Yoshitake H, Maruyama M, Takamori K, Ogawa H, Hasegawa A \& Araki Y 2009 Distribution of molecular epitope for Ts4, an antisperm auto-monoclonal antibody in the fertilization process. Journal of
Reproduction and Development 55 240-246. (https://doi.org/10.1262/ jrd.20156)

Stagg J 2012 The double-edge sword effect of anti-CD73 cancer therapy. Oncoimmunology 1 217-218. (https://doi.org/10.4161/onci.1.2.18101)

Stagg J \& Smyth MJ 2010 Extracellular adenosine triphosphate and adenosine in cancer. Oncogene 29 5346-5358. (https://doi.org/10.1038/ onc.2010.292)

Stenflo J \& Fernlund P 1982 Amino acid sequence of the heavy chain of bovine protein C. Journal of Biological Chemistry 257 12180-12190.

Sun S \& Zhang H 2015 Identification and validation of atypical N-glycosylation sites. Analytical Chemistry 87 11948-11951. (https:// doi.org/10.1021/acs.analchem.5b03886)

Suzuki K, Watanabe T, Sakurai S, Ohtake K, Kinoshita T, Araki A, Fujita T, Takei H, Takeda Y, Sato Y et al. 1999 A novel glycosylphosphatidyl inositol-anchored protein on human leukocytes: a possible role for regulation of neutrophil adherence and migration. Journal of Immunology 162 4277-4284.

Takayama T, Mishima T, Mori M, Jin H, Tsukamoto H, Takahashi K, Takizawa T, Kinoshita K, Suzuki M, Sato I et al. 2005 Sexually dimorphic expression of the novel germ cell antigen TEX101 during mouse gonad development. Biology of Reproduction 72 1315-1323. (https://doi. org/10.1095/biolreprod.104.038810)

Tarentino AL, Gomez CM \& Plummer TH Jr 1985 Deglycosylation of asparagine-linked glycans by peptide: N-glycosidase F. Biochemistry $\mathbf{2 4}$ 4665-4671. (https://doi.org/10.1021/bi00338a028)

Thompson LF, Eltzschig HK, Ibla JC, Van De Wiele CJ, Resta R, MoroteGarcia JC \& Colgan SP 2004 Crucial role for ecto-5'-nucleotidase (CD73) in vascular leakage during hypoxia. Journal of Experimental Medicine 200 1395-1405. (https://doi.org/10.1084/jem.20040915)

Tsukamoto H, Yoshitake H, Mori M, Yanagida M, Takamori K, Ogawa H, Takizawa T \& Araki Y 2006 Testicular proteins associated with the germ cell-marker, TEX101: involvement of cellubrevin in TEX101-trafficking to the cell surface during spermatogenesis. Biochemical and Biophysical Research Communications 345 229-238. (https://doi.org/10.1016/j. bbrc.2006.04.070)

Tulsiani DR, Yoshida-Komiya H \& Araki Y 1997 Mammalian fertilization: a carbohydrate-mediated event. Biology of Reproduction 57 487-494. (https://doi.org/10.1095/biolreprod57.3.487)

Valliere-Douglass JF, Kodama P, Mujacic M, Brady LJ, Wang W, Wallace A, Yan B, Reddy P, Treuheit MJ \& Balland A 2009 Asparagine-linked oligosaccharides present on a non-consensus amino acid sequence in the $\mathrm{CH} 1$ domain of human antibodies. Journal of Biological Chemistry 284 32493-32506. (https://doi.org/10.1074/jbc.M109.014803)

Valliere-Douglass JF, Eakin CM, Wallace A, Ketchem RR, Wang W, Treuheit MJ \& Balland A 2010 Glutamine-linked and non-consensus asparagine-linked oligosaccharides present in human recombinant antibodies define novel protein glycosylation motifs. Journal of Biological Chemistry 285 16012-16022. (https://doi.org/10.1074/jbc. M109.096412)

Whiley PA, Miyamoto Y, McLachlan RI, Jans DA \& Loveland KL 2012 Changing subcellular localization of nuclear transport factors during human spermatogenesis. International Journal of Andrology 35 158169. (https://doi.org/10.1111/j.1365-2605.2011.01202.x)

Wong-Madden ST \& Landry D 1995 Purification and characterization of novel glycosidases from the bacterial genus Xanthomonas. Glycobiology 5 19-28. (https://doi.org/10.1093/glycob/5.1.19)

Xie Y, Khan R, Wahab F, Hussain HMJ, Ali A, Ma H, Jiang H, Xu J, Zaman Q, Khan M et al. 2019 The testis-specifically expressed Dpep3 is not essential for male fertility in mice. Gene 711. (https://doi.org/10.1016/j. gene.2019.06.015] 143925.

Yang WX, Jefferson H \& Sperry AO 2006The molecular motor KIFC1 associates with a complex containing nucleoporin NUP62 that is regulated during development and by the small GTPase RAN. Biology of Reproduction 74 684-690. (https://doi.org/10.1095/biolreprod.105.049312)

Yoshitake H, Shirai Y, Mochizuki Y, Iwanari H, Tsubamoto H, Koyama K, Takamori K, Ogawa H, Hasegawa A, Kodama T et al. 2008a Molecular diversity of TEX101, a marker glycoprotein for germ cells monitored with monoclonal antibodies: variety of the molecular characteristics according to subcellular localization within the mouse testis. Journal of Reproductive Immunology 79 1-11. (https://doi.org/10.1016/j. jri.2008.05.001) 
Yoshitake H, Tsukamoto H, Maruyama-Fukushima M, Takamori K, Ogawa H \& Araki Y 2008b TEX101, a germ cell-marker glycoprotein, is associated with lymphocyte antigen 6 complex locus $\mathrm{k}$ within the mouse testis. Biochemical and Biophysical Research Communications 372277 282. (https://doi.org/10.1016/j.bbrc.2008.05.088)

Yoshitake H, Yanagida M, Maruyama M, Takamori K, Hasegawa A \& Araki Y 2011 Molecular characterization and expression of dipeptidase 3, a testis-specific membrane-bound dipeptidase: complex formation with TEX101, a germ-cell-specific antigen in the mouse testis. Journal of Reproducitve Immunology 90 202-213. (https://doi.org/10.1016/j. jri.2011.04.010)

Yoshitake H, Hashii N, Kawasaki N, Endo S, Takamori K, Hasegawa A, Fujiwara H \& Araki Y 2015 Chemical characterization of N-linked oligosaccharide as the antigen epitope recognized by an anti-sperm auto-monoclonal antibody, Ts4. PLOS ONE 10 e0133784. (https://doi. org/10.1371/journal.pone.0133784)

Yoshitake H, Oda R, Yanagida M, Kawasaki Y, Sakuraba M, Takamori K, Hasegawa A, Fujiwara H \& Araki Y 2016 Identification of an anti- sperm auto-monoclonal antibody (Ts4)-recognized molecule in the mouse sperm acrosomal region and its inhibitory effect on fertilization in vitro. Journal of Reproductive Immunology 115 6-13. (https://doi. org/10.1016/j.jri.2016.04.001)

Zhang B 2012 CD73 promotes tumor growth and metastasis. Oncoimmunology 1 67-70. (https://doi.org/10.4161/onci.1.1.18068)

Zimmermann H, Zebisch M \& Strater N 2012 Cellular function and molecular structure of ecto-nucleotidases. Purinergic Signalling 8 437502. (https://doi.org/10.1007/s11302-012-9309-4)

Received 25 July 2019

First decision 30 August 2019

Revised manuscript received 20 September 2019

Accepted 4 October 2019 